\title{
Sustainable Development and Renewable Energy from Biomass in Peru - Overview of the Current Situation and Research With a Bench Scale Pyrolysis Reactor to Use Organic Waste for Energy Production
}

\author{
Michael Klug ${ }^{1,2}$, Nadia Gamboa ${ }^{1} \&$ Karl Lorber $^{2}$ \\ ${ }^{1}$ Pontificia Universidad Catolica de Peru, Seccion Quimica, Lima, Peru \\ ${ }^{2}$ Montanuniversität Leoben, Leoben, Austria \\ Correspondence: Michael Klug, Pontificia Universidad Catolica de Peru Av. Universitaria 1801, San Miguel, \\ Lima 32, Perú. Tel: 51-991-703-259. E-mail: klugmichl@hotmail.com
}

Received: May 2, 2013 Accepted: June 26, 2013 Online Published: July 24, 2013

doi:10.5539/jsd.v6n8p130 URL: http://dx.doi.org/10.5539/jsd.v6n8p130

\begin{abstract}
Peru is an interesting emerging market with a stable development and economic growth during the last years. This growth also brings new challenges for sustainable development. The rising energy demand and the increasingly high volumes of waste need sustainable solutions. Thus far, Peru has a big unused potential in the production of bioenergy, especially a big amount of unused biomass. With the construction of a small Flash Pyrolysis Reactor at the Pontificia Universidad Católica del Perú (PUCP), the research of the potential of different biomass feedstock for pyrolysis process has started. The first results and an overview of the current situation in Peru are presented in this paper.
\end{abstract}

Keywords: Peru, sustainable development, biomass, bioenergy, pyrolysis

\section{Introduction}

Peru is a megadiverse country in a constant economic growth that urgently demands careful sustainable development to protect and preserve its natural wealth. The territory is located in tropical and subtropical areas in South America. It would draw the conclusion that the climate should be warm and humid but, due to the presence of the Andes and a complex system of ocean currents and movements of air masses (South Pacific Anticyclone), a rich variety of climates is generated. Therefore, connected to its geological and ecological features, Peru becomes a megadiverse country.

According to Pulgar Vidal (1940), Peru has eight different natural regions (Chala, Yunga, Quechua, Suni, Puna, Janca, Rupa Rupa and Omagua) and one maritime region (Mar Peruano). However, the land could be broadly divided into three main regions: an arid desert region (Costa), mountains (Sierra) and a tropical forest (Selva) into which those, proposed by Pulgar Vidal, can be included. On the other hand, 84 different life zones, according to Holdridge, can be found in Peru, the country with the largest amount (Figure 1) in the world. Only in the Peruvian Amazon exists around 1700 varieties of birds as well as many species of mammals, fish and insects, being part of a great variety of unique fauna. Moreover, the Peruvian flora has the greatest variety of domesticated plants in the world; for example, there are over one thousand varieties of potatoes. National reserves in Peru are the richest sources of natural resources in the world (MINAM, 2013).

The area dedicated to agriculture is roughly $24 \%$ of the total land, and the forests cover $70 \%$ of the national territory, including the tropical rainforest (Khwaja, 2010). The economy of this developing country grew $6.92 \%$ in the year 2011 thanks to the mining sector as the most important income (Indexmundi, 2012). Around 91.5\% of the Peruvians living in urban areas have access to public water systems compared to only $52.3 \%$ in rural areas. It is also a fact that not more than $72.5 \%$ of rural households have electric lighting in comparison to $98.8 \%$ of urban ones. Another alarming figure shows that $34.7 \%$ of the population suffers from calorie deficit $(23.9 \%$ in Lima and up to $48.9 \%$ in rural areas), and $13.9 \%$ of the children under 5 years old suffers from chronic malnutrition. These numbers show that Peru has a state of food insecurity and, for this reason, it must be avoided that food production is affected by the bioenergy industry. It is important to emphasize that the lack of food and the rise of food prices are not only related to competition by liquid biofuels, these are also associated with low levels of income, inadequate use of food and other multiple factors (INEI, 2012). On October 2012, 167 social 
conflicts in Peru were officially registered, 66 of them were latent and over $63 \%$ of the total were social-environmental conflicts, in most cases caused by mining activities (Defensoría del Pueblo, 2012).

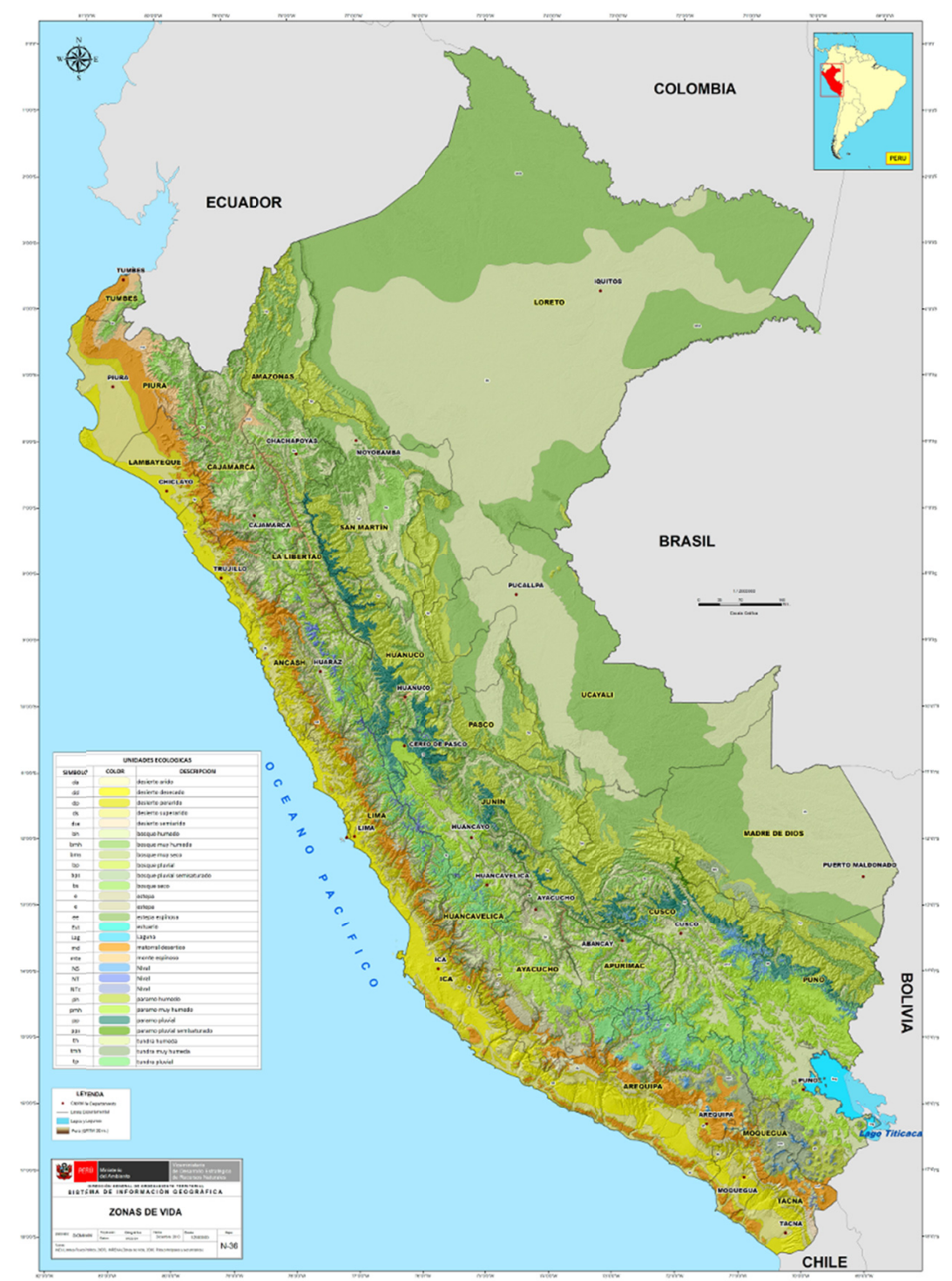

Figure 1. Life zones in Peru (MINAM, 2013)

The energy mix in Peru consists of 56\% of fossil fuels, $27 \%$ produced with renewable energies and $17 \%$ with natural gas (MINEM, 2009). The aim of the Peruvian government is to increase the renewable energy quota up to $33 \%$ until 2030. For this purpose, the government began to create legal frameworks to raise the use of renewable energy; for example, normal fuels have to be mixed with biofuels. The Peruvian law (MINEM, 2005) has demanded an additive of:

- $\quad 5 \%$ biodiesel in diesel since 2011 , and

- $7.8 \%$ ethanol in gasoline since 2010 .

So far, the local demand is fulfilled with first generation biofuels, which leads to different issues (FAO, 2008), such as:

- rainforest deforestation,

- monocultures,

- $\quad$ food vs. energy, 
- erosion,

- land use change,

- increased water demand,

- increased food prices, and

- others.

Some projects in renewable energy field have been developed in the country, such as the use of sugar cane for the production of ethanol. Peru counts on 12 refineries with potential production capacity of 64 million liters per year. The high water demand of sugar cane and the water constraints in some regions of Peru raise the question whether it is more important to grow agrobiofuels instead of prioritizing crops for food production. For biodiesel production, oil palm (Elaeis guineensis) and jatropha (Jathropa curcas) are potential feedstock with some projects using jatropha at experimental stage to date. On the other hand, there is an installed area of more than 44 882 ha for oil palm, 38\% of the total area in production, 34\% in growth and the rest in nurseries (Khwaja, 2010).

Life cycle analyses of biofuel production in the Peruvian Amazon show that not all production ways make environmental sense. Nowadays, the fact that biofuel production is ecological or not in Peru strongly depends on the previous land use where the energy crops are planted. The most pessimistic scenarios are those where primary forests are destroyed to get farmland for energy crops (SVN, 2009). It can be shown from the carbon debt calculated for eight different scenarios. Oil palm and jatropha crops have positive environmental impacts on degraded forest land with values of -8.1 and $-9.5 \mathrm{t} \mathrm{CO}_{2} \mathrm{eq} / \mathrm{ha}$, while biofuel production, in primary forests, incurs debts (the amount of years necessary using biodiesel in order to compensate for the carbon emissions caused by the land use change to produce biodiesel) of 40 and 140 years for oil palm and jatropha (SVN, 2009).

The most commonly bioenergy used in Peru is solid biofuel, as dung, firewood and charcoal, $10-12 \%$ of total energy consumption is based on solid biomass. For the generation of electric power, the most important bioenergy resource is biogas generated by the anaerobic decomposition of plant and animal waste. Used residues include bagasse, rice husk, forestry waste, grain chaff, and remains from the poultry, beef cattle and pig farming. From January 2012 to September 2012, 114.9 GWh of electricity were produced by biogas, nearly twice compared to the production in the same period in the 2011 (OSINERGMIN, 2012).

The total offer of available biomass in Peru for the production of energy is 272 million metric tons according to WISDOM (Woodfuels Intergrated Supply/Demand Overview Mapping) analysis carried out by FAO (Felix \& Rosell, 2010). This number includes 16 million tons of organic waste yearly available from agricultural and forest industries. The remaining 256 million tons represent the potential of woody biomass from the natural forests in Peru. The tropical forest zone has the biggest amount of available forest biomass, while the arid coastal region and the south of the Sierra have only a short supply of biomass. This heterogeneous distribution of resources is the result of geographical and climate variations that characterize the Peruvian territory. However, WISDOW analysis shows that many regions of the country have significant volumes of biomass that could potentially be used to provide local energy. For instance, the woody biomass and forest industry residues could be not only used for direct or indirect generation of local energy, but also transported over long distances as briquettes, coal, gas, etc. (Felix \& Rosell, 2010). The production potential data for renewable energies, energy efficiency and co-generation in Peru, expressed in tons of oil equivalent (Toe), is shown in Table 1.

Table 1. Potential production for renewable energy, energy efficiency and co-generation in Peru (i.e., any authoritative assessments) (ECLAC-UN \& GTZ, 2004)

\begin{tabular}{cr}
\hline Source & Production Potential \\
\hline Hydroenergy & 2852000 Toe $/$ year \\
Fuel wood & 66000000 Toe $/$ year \\
Agricultural waste & 530000 Toe $/$ year \\
Livestock waste & 150000 Toe $/$ year \\
Agroindustrial waste & 395000 Toe $/$ year \\
Urban waste & $236000 \mathrm{Toe} /$ year \\
Wind power & $450-5.000 \mathrm{kWh} / \mathrm{m}^{2} /$ year \\
Solar energy & $4-5 \mathrm{kWh} / \mathrm{m}^{2}$ \\
\hline
\end{tabular}




\section{Pyrolysis and Its Potential}

Climate change affects globally and the challenge now is to find solutions and technologies to diminish the global warming in order to ensure a healthy clean environment to next generations. To make energy consumption more efficient and reduce greenhouse gas emissions it is necessary to face the problem immediately (IPCC-WGIII, 2007). Figure 2 shows a positive carbon cycle, like today, and a closed carbon cycle; but to reduce the $\mathrm{CO}_{2}$ in the atmosphere, a negative carbon cycle is necessary.
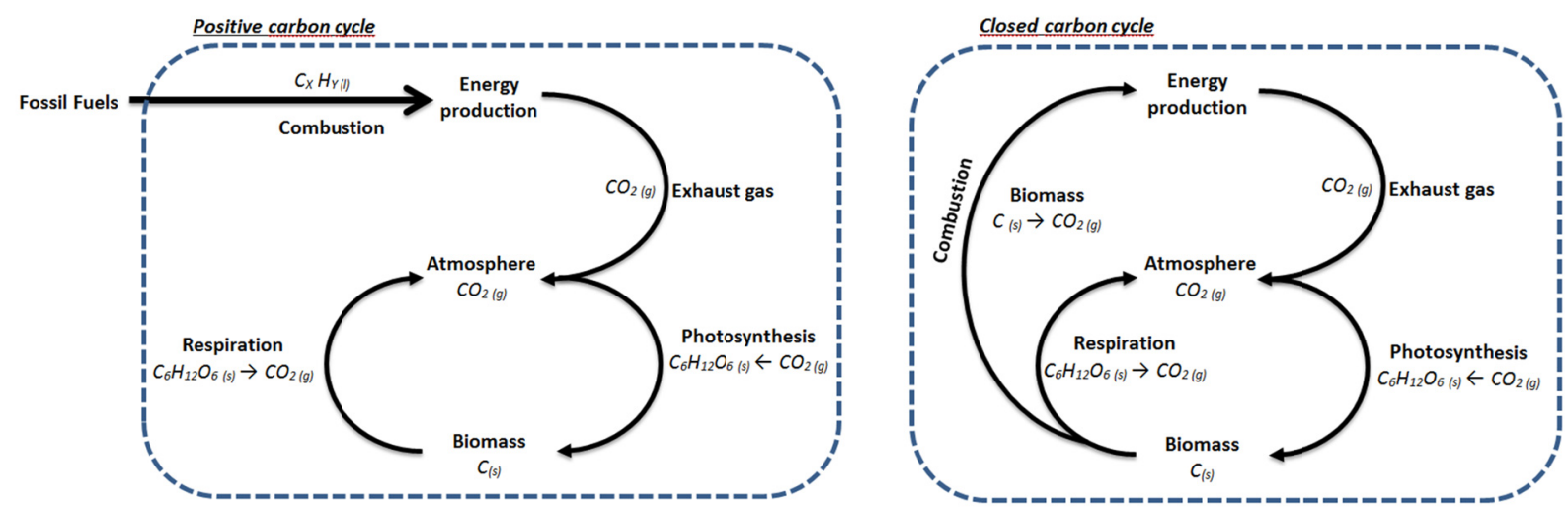

Figure 2. Positive and closed carbon cycle (Thomsen, Hauggaard-Nielsen, Bruun, \& Ahrenfeldt, 2011)

The use of pyrolysis (climate neutral fuels production technology) products leads to a closed carbon cycle but if coal (biochar), which is a pyrolysis product, was used as fertilizer, then the result would be a negative carbon cycle. Another proposal for closed carbon cycle is the full combustion of biomass combined with Carbon Capture and Storage technology (Thomsen et al., 2011).

Pyrolysis is a thermal decomposition of organic material occurring in the absence of oxygen. Likewise, it is always one of the first steps in combustion and gasification processes followed by total or partial oxidation of the intermediate products. Lower process temperature and longer vapor residence times favor charcoal production. High temperature and longer residence time increase the biomass conversion to gas, but moderate temperature and short vapor residence time are ideal conditions for producing liquids. Fast pyrolysis for liquid fuel production is of particular interest, as liquids are transportable and easy to store because of the good energy bulk density relationship compared to other feedstock (Figure 3) (Professional Engineering Publishers, 2003). Figure 4 shows a schematic pattern of biomass decomposition in a pyrolysis process of wheat straw.

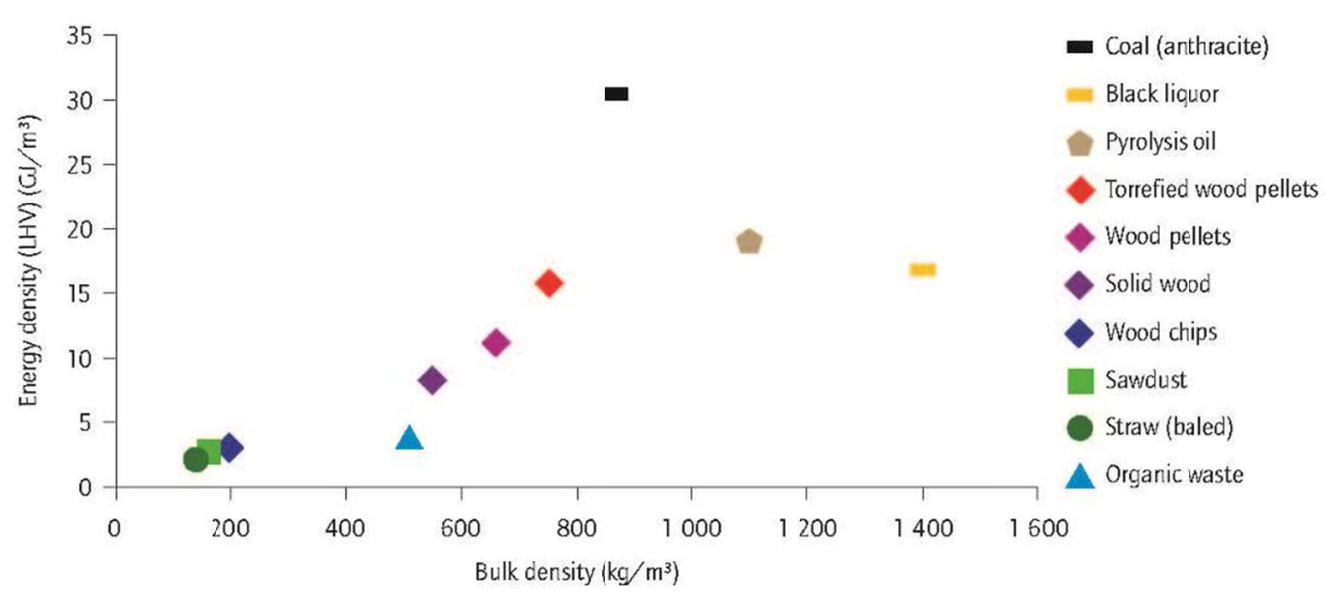

Figure 3. Comparison of bulk density and energy density (IAE, 2012) 


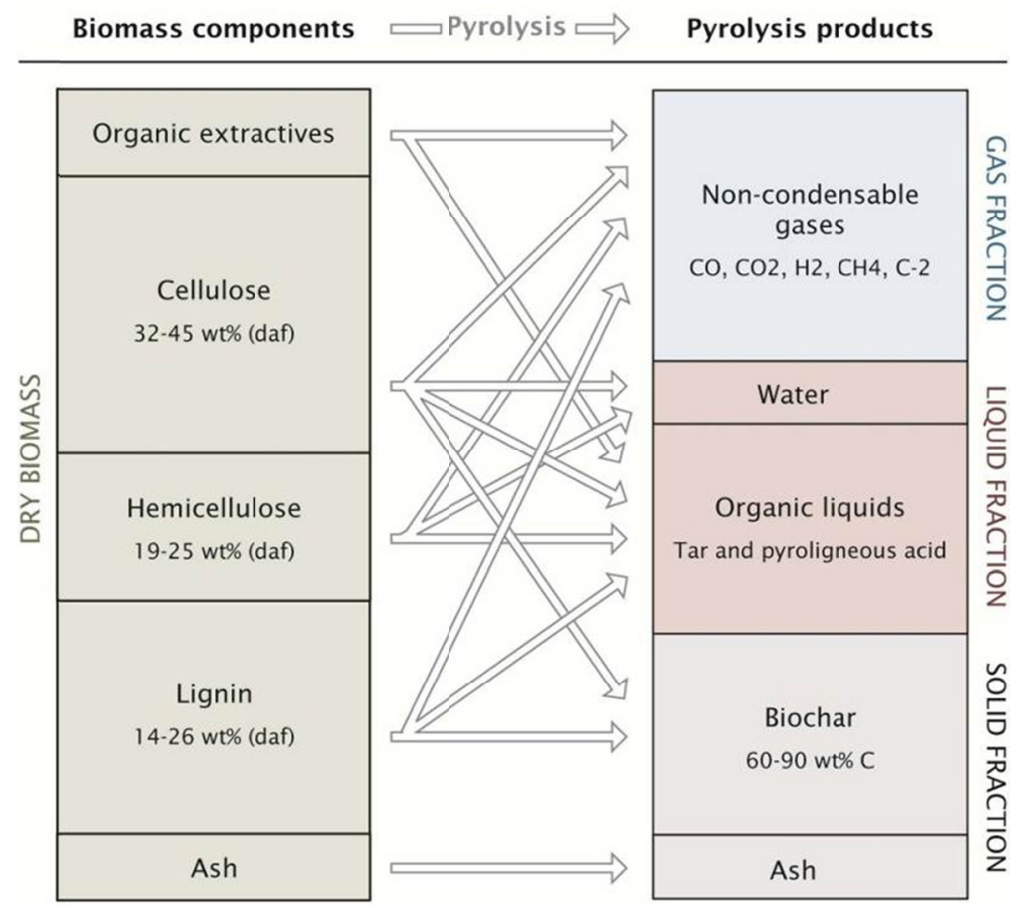

Figure 4. Generalized decomposition pattern of biomass from thermal decomposition in pyrolysis (Thomsen et al., 2011)

Pyrolysis processes can be divided into several subcategories, regarding the design and the operation conditions. The variety of reactor designs and processes comes from diverse feedstock and depends on the required product distribution. A basic pyrolysis processes classification, including a distribution of mass percentage on products, is presented in Table 2. Table 3 presents a summary of Fast Pyrolysis Reactor systems. It shows the key features of each reactor system and the status of their development (Pyne, 2012).

Table 2. Distribution of mass percentage on products of various pyrolysis processes (Bridgewater, 2007)

\begin{tabular}{cccc}
\hline & $\begin{array}{c}\text { Liquid } \\
\text { (bio-oil) }\end{array}$ & $\begin{array}{c}\text { Solid } \\
\text { (biochar) }\end{array}$ & $\begin{array}{c}\text { Gas } \\
\text { (process gas) }\end{array}$ \\
\hline $\begin{array}{c}\text { FAST PYROLYSIS } \\
\text { Moderate temperature }\left(>500^{\circ} \mathrm{C}\right) \\
\text { Short vapor residence time }(<2 \mathrm{~s})\end{array}$ & $75 \%(25 \%$ water $)$ & $12 \%$ & $13 \%$ \\
\hline $\begin{array}{c}\text { INTERMEDIATE PYROLYSIS } \\
\text { Low-moderate temperature }\left(<500^{\circ} \mathrm{C}\right) \\
\text { Moderate hot vapor residence time }\end{array}$ & $50 \%(50 \%$ water $)$ & $25 \%$ & $25 \%$ \\
\hline $\begin{array}{c}\text { SLOW PYROLYSIS } \\
\text { Low-moderate temperature }\left(<500^{\circ} \mathrm{C}\right) \\
\text { Long residence time }\end{array}$ & $30 \%(70 \%$ water $)$ & $35 \%$ & $35 \%$ \\
\hline $\begin{array}{c}\text { GASIFICATION } \\
\text { High temperature }\left(>800{ }^{\circ} \mathrm{C}\right) \\
\text { Long vapor residence time }\end{array}$ & $5 \%(5 \%$ water $)$ & $10 \%$ & $85 \%$ \\
\hline
\end{tabular}


Table 3. Overview of fast pyrolysis reactor features for bio-oil production (Pyne, 2012)

\begin{tabular}{|c|c|c|c|c|c|c|c|c|}
\hline Property & Status ${ }^{1}$ & $\begin{array}{c}\text { Bio-oil } \\
\text { yield } \\
{[\mathrm{wt} \%, \mathrm{dry}} \\
\text { biomass }]\end{array}$ & Complexity & $\begin{array}{c}\text { Feed size } \\
\text { specification }\end{array}$ & $\begin{array}{c}\text { Inert gas } \\
\text { requirements }\end{array}$ & $\begin{array}{c}\text { Specific } \\
\text { reactor size }\end{array}$ & Scale up & Gas \\
quality \\
\hline Fluid bed & Commercial & 75 & Medium & High & High & Medium & Easy & Low \\
\hline $\begin{array}{c}\text { CFB \& Transported } \\
\text { bed }\end{array}$ & Commercial & 75 & High & High & High & Medium & Easy & Low \\
\hline Rotating cone & Demonstration & 70 & High & High & Low & Low & Medium & High \\
\hline Entrained flow & Laboratory & 60 & Medium & High & High & Medium & Easy & Low \\
\hline Ablative & Laboratory & 75 & High & Low & Low & Low & Difficult & High \\
\hline Screw or Auger & Pilot & 60 & Medium & Medium & Low & Low & Medium & High \\
\hline Vacuum & None & 60 & High & Low & Low & High & Difficult & Medium \\
\hline
\end{tabular}

Notes: 1) commercial (2 t/h - $20 \mathrm{t} / \mathrm{h})$; demonstration (200-2000 kg/h); pilot (20-200 kg/h); laboratory (1-20 kg/h).

2) Colors: green $=$ favorable feature; purple $=$ moderate feature; blue $=$ unfavorable feature.

\section{Flash Pyrolysis}

Fast or flash pyrolysis occurs in a period of few seconds or less. Therefore, chemical reaction kinetics, heat and mass transfer processes as well as phase transition phenomena play important roles. The critical issue is to bring the reacting biomass particle to the optimum process temperature and minimize its exposure to the intermediate (lower) temperatures that favor formation of charcoal. It is possible to reach this goal by using small particles, for example, in the fluidized bed processes. Another way is to transfer heat very fast only to the particle surface that contacts the heat source, which is applied in ablative processes (Bridgewater, 2001).

In fast pyrolysis, the biomass decomposes to generate mostly vapors, aerosols and some charcoal. After cooling and condensation, a dark brown liquid is formed and its heating value is around half of that of conventional fuel oil. While it is related to the traditional pyrolysis processes in charcoal making, fast pyrolysis is an advanced process with carefully controlled parameters to give high yields of liquid products (Bridgwater, 2008).

The main product bio-oil is obtained in yields up to $75 \% \mathrm{wt}$ on dry feed basis, (in the most developed processes) along with by-products such as charcoal and gas. Bio-oil is a liquid mixture of oxygenated compounds containing various functional chemical groups, such as carbonyl, carboxyl and phenolic components. The two by-products (gas and biochar) can be used to provide the process heat requirements, thus there are finally no other waste streams left than flue gas and ash (Pyne, 2012).

Based on the fact that there is a lot of unused potential biomass and a lack of appropriate local technology in Peru, a bench-scale Flash Pyrolysis Reactor was constructed at the Pontificia Universidad Católica del Perú (PUCP) to carry out first experiments with different feedstock. One of the goals was to use only materials and instruments available in Peru; therefore, nothing has to be imported.

For the first experiments, coffee ground was used. Peru is not only exporting special kinds of coffee all over the world but also the consumption within the country is rising. In general, coffee is the most widely traded tropical agricultural commodity in the world mainly used for beverages, with a production of 93.4144 million bags (i.e. 4750000 in Peru) in the year 2012 (one bag weights 60 kilograms). Depending on coffee varieties, the oil amount varies from 11 to $20 \mathrm{wt} \%$ (ICO, 2012). With the increase of the coffee consumption, the volume of coffee ground is also growing. Normally, coffee ground is put into the household waste that goes mainly to landfills. In some cases, this feedstock is used as compost or deodorizer, but a big amount is unused and can be turned into renewable energy (Jin et al., 2012).

\section{Results}

After planning the small bench-scale reactor, the parts were constructed and assembled in one laboratory at PUCP. The reactor has a fluidized bed and can operate between 450 and $600^{\circ} \mathrm{C}$. Specifications of the reactor are presented in Table 4. 
Table 4. Specifications of the lab-scale reactor

\begin{tabular}{cc}
\hline Reactor type & Fluidized bed \\
\hline Bed material & Quartz sand \\
Amount of quartz sand & $100-250 \mathrm{~g}$ \\
Particle size of quartz sand & $350-450 \mu \mathrm{m}$ \\
Process temperature & $450-600{ }^{\circ} \mathrm{C}$ \\
Process gas & Nitrogen \\
Feeding rate & $<300 \mathrm{~g} / \mathrm{h}$ \\
Particle size of feedstock & $<1 \mathrm{~mm}$ \\
Residence time in the reactor & $0.5-2 \mathrm{~s}$ \\
Heating & Electric \\
Volume of the reactor & $1.03 \mathrm{~L}$ \\
Temperature control & Thermo Couple (Type K) \\
\hline
\end{tabular}

The parts of the reactor were constructed with the support of local enterprises and all the other materials and components used are available in Peru as it was proposed. The used steel is a SS 304 (18.8) to resist high temperatures. The condenser and the other glass parts are made of borosilicate glass to support the changes in temperature. A cryostat is cooling down the condenser to $-15^{\circ} \mathrm{C}$. The first experiments have been made with ground coffee at temperatures between 450 and $550^{\circ} \mathrm{C}$. They demonstrate that the reactor works well and produces the three expected products: gas, pyrolysis oil and coal as shown in Figures 5-7.

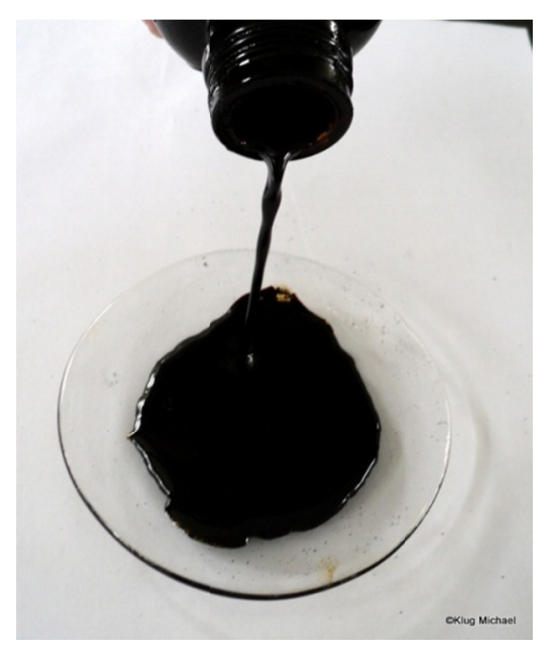

Figure 5. Pyrolysis oil from coffee ground

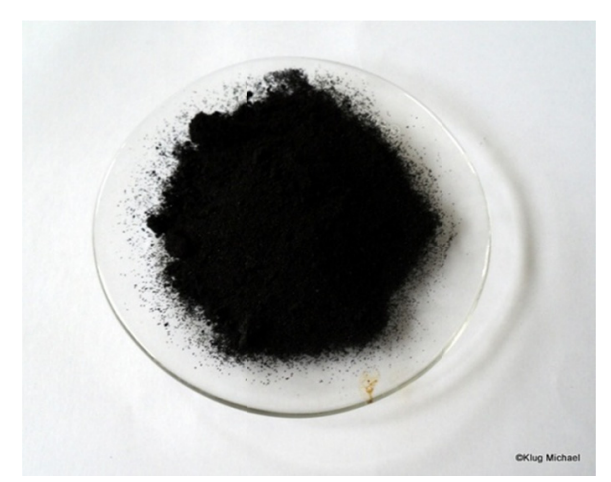

Figure 6. Coke from the pyrolysis process 


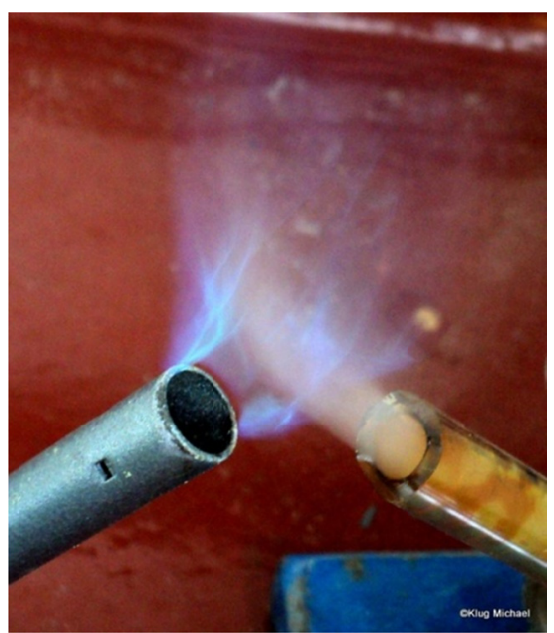

Figure 7. Burning of the pyrolysis gas

Thus far, the efforts for the next steps are focused on getting a more efficient process and easier handling as well as to obtain higher product yields and to characterize the pyrolysis oil.

\section{Discussion}

Peru has to step up for following a sustainable way to protect its natural resources but also the human needs. There are many unused resources available for the production of green energy in Peru. Foreign investors come into the land slowly to use these resources, for example, building wind parks and solar energy farms. However, this is also an opportunity for Peruvian enterprises and researchers to make profit and improvements. A way to ensure a sustainable progress is to make research for developing green technologies, but the challenges to accomplish research in a developing country are quite different compared to Europe or United States. One of the main issues is to find financial aid. The budget is not enough to cover research projects and mainly private institutions as PUCP have limited financial resources, but it is evident that the public focus in these regions is to cover basic needs of the population such as health care, education opportunities, and to fight against undernourishment, etc. Another hurdle for successful research projects is to find the required materials with high quality and available in smaller dimensions not like those needed by the industry. Likewise, due to the low number of research projects, the availability of materials or parts manufacturers for small scale R\&D is very limited. In comparison to developed countries, where anyone can find nearly every product or service just searching on internet, this possibility only exists in a much more reduced form, making necessary to spend more time and work for this aspect of the project. The ability to improvise adequately is very important. On the other hand, it is also difficult to find people with solid experience in these fields. Another important difference to R\&D activities in developed countries is the lack of bonds between universities and industries that make research for applied research nearly impossible. With the granting of scholarships for foreign students and researchers, young professionals from developed countries could be enthusiastic to start or take part in technical research projects for a sustainable development; alike the one reported in this paper. The other way, scholarships for students from developing countries to study in Europe or North America, is a big success; however, these students sometimes do not come back and stay abroad since they find opportunities they will not get in their native lands.

The first experiments with the described pilot plant show that it is functioning, but a lot of work is still necessary to find optimal process parameters. In addition, experiments with different feedstock available in Peru should be run in the future. If enough results are collected and analyzed, the aim is to scale up for a bigger demonstration plant for further research. It is a systematic process for a sustainable development by using the potential of renewable energy in Peru. As the economy and industrial sectors are growing, the need for energy will also rise and, hopefully, these demands could be covered with a high percentage of green energy.

However, not only environmental facts are important for sustainable development. In the land of the Incas, more than 150 social conflicts are recently going on. The economic and industrial progress should not be forced on the shoulders of the poorest population, for not to raise the number of social conflicts at the same time. Therefore, people from all social classes and ethnicities must be included in the developing processes and their decisions and worries should not be ignored. 
Peru is a gifted land with a lot of potential to grow. Society and authorities not only should think in profit but also in sustainable development to protect its natural treasures and to provide social justice.

\section{Acknowledgements}

The authors wish to thank Dirección de Gestión de la Investigación (VRI-PUCP) for the funding, Proyectos 70243.0145/2011 and 70243.0087/2012

We wish to thank Ms. Ada Tresierra, Oficina de Propiedad Intelectual, Vicerrectorado de Investigación, PUCP, for the English review.

\section{References}

Bridgwater, A. (2001). Progress in Thermochemical Biomass Conversion, 2. Oxford: Blackwell Science. http://dx.doi.org/10.1002/9780470694954

Bridgewater, A. (2007). IAE Bioenergy Update 27: Biomass Pyrolysis. Biomass and Bioenergy, 31(4), 1-5. http://dx.doi.org/10.1016/j.bbr.2011.03.031

Bridgwater, A. (2008). Fast Pyrolysis of Biomass: A Handbook, 2(2). Great Britain: Cpl Pr.

Defensoría del Pueblo. (2012). Reporte de Conflictos Sociales $N^{o}$ 104. Lima -Peru.

ECLAC-UN, \& GTZ. (2004). Renewable Energy Sources in Latin America and the Caribbean: Situation and Policy Proposals. Retrieved March 11, 2013, from http://www.eclac.org/cgi-bin/getProd.asp?xml=/publicaciones/xml/1/14981/P14981.xml\&xsl=/dmaah/tpl-i/ p9f.xsl\&base=/dmaah/tpl/top-bottom.xsl

FAO (Food and Agriculture Organization of the United Nations). (2008). State of Food and Agriculture Biofuels Prospects, Risks and Opportunities. Rome: FAO.

Felix, E., \& Rosell, C. (2010). Bioenergía y seguridad alimentaria "BEFS”- El análisis de BEFS para el PeruCompendio té Acknowledgements.

ICO. (2013). International Coffee Organization - World Coffee Trade. Retrieved July 11, 2013, from http://www.ico.org/prices/po.htm

Indexmundi. (2012). Peru Economy Profile 2012. Retrieved March 11, 2013, from http://www.indexmundi.com/peru/economy_profile.html

INEI (Peruvian National Insitute of Statistics and Computers). (2012). Condiciones de Vida en el Perú Abril-Mayo-Junio 2012. Número 3. Peru, Lima. Retrieved from http://www.inei.gob.pe/web/biblioinei/BoletinFlotante.asp?file=15018.pdf

IPCC-WGIII. (2007). IPCC Fourth Assessment Report (AR4) - Climate Change 2007: Mitigation of Climate Change. Cambridge / New York: Cambridge University.

Jin, P. B., Hang, S. C., Yeon, S. C., Hoon, C. P., \& Seock, J. K. (2012). Fast pyrolysis of coffee grounds: Characteristics of product yields and biocrude oil quality. Energy, 47(1), 17-24. http://dx.doi.org/10.1016/j.energy.2012.06.03

Khwaja, Y. (Ed). (2010). Bioenergy and food security - The BEFS Analysis for Peru Supporting the policy machinery in Peru. Rome: FAO - BEFS.

MINEM (Peruvian Ministry of Energy and Mines). (2005). Ley de Promoción del Mercado de Biocombustibles Ley 28054. DECRETO SUPREMO No 024-2011-EM. Peru, Lima.

MINEM (Peruvian Ministry of Energy and Mines). (2009). Resumen de la Matriz Energética del Perú 2009. Retrieved March 11, 2013, from http://www.minem.gob.pe/estadistica.php?idSector=12\&idEstadistica $=6424$

MINAM (Peruvian Ministry of Environment). (2013). Zonas de Vida. Retrieved March 11, from http://geoservidor.minam.gob.pe/atlasperu/Default.asp?WCI=PltEcosistemas\&WCE=1.2.2

Osinergmln. (2012). Reporte Estadístico Septiembre - Operación del Sector Eléctrico. Retrieved March 11, 2013, from http://www2.osinerg.gob.pe/Publicaciones/pdf/OperSecElectrico/OSENOV2012.pdf

Professional Engineering Publishers. (2003). Renewable Bioenergy - Technologies, Risks and Rewards. London: John Wiley \& Sons.

Pyne. (2012). IEA Bioenergy, Task 34 - Pyrolisis. Retrieved March 11, 2013, from http://www.pyne.co.uk/?_id=18 
SVN. (2009). Impactos ambientales de la producción de biocombustibles en la Amazonía Peruana - Análisis de Ciclo de Vida de los Biocombustibles de Palma Aceitera y Jatropha Curcas. Lima: SVN.

Thomsen, T., Hauggaard-Nielsen, H., Bruun, E., \& Ahrenfeldt, J. (2011). The potential of pyrolysis technology in climate change mitigation - influence of process design and-parameters, simulated in SuperPro Designer Software. Roskilde: Danmarks Tekniske Universitet, Risø Nationallaboratoriet for Bæredygtig Energi. (Denmark. Forskningscenter Risoe. Risoe-R; No. 1764(EN)).

\section{Copyrights}

Copyright for this article is retained by the author(s), with first publication rights granted to the journal.

This is an open-access article distributed under the terms and conditions of the Creative Commons Attribution license (http://creativecommons.org/licenses/by/3.0/). 